\title{
Early treatment with the twin-block appliance is effective in reducing overjet and severity of malocclusion
}

\author{
Is the twin-block orthodontic appliance effective in early treatment of \\ developing class II division 1 malocclusion?
}

\author{
O'Brien K, Wright J, Conboy F, et al. Effectiveness of early \\ orthodontic treatment with the twin-block appliance: $a$ \\ multicenter, randomized, controlled trial. Part 1: dental and \\ skeletal effects. Am J Orthod Dentofacial Orthop 2003; \\ 124:234-243
}

Design This was a multicentre randomised controlled trial in hospitalbased orthodontic practice.

Intervention Children of age 8-10 years who had class II division 1 malocclusion with a minimum 7-mm overjet (measured clinically) and absence of a craniofacial syndrome were randomly allocated to receive treatment with a twin-block appliance or to an untreated, control group if they were willing to take part in the study and had parental approval to do so.

Outcome measure The outcome measures were the antero-posterior relationship of the maxilla to the mandible after treatment, overjet and dental malocclusion, as recorded by the peer assessment rating (PAR).

Results Early treatment with twin-block appliances resulted in reduction of overjet, correction of molar relationships, and reduction in severity of malocclusion (Table 1 ).

Table 1. Changes in overjet and peer assessment rating (PAR).

\begin{tabular}{|c|c|c|c|c|}
\hline \multirow[t]{2}{*}{ Group } & \multicolumn{2}{|c|}{$\begin{array}{l}\text { Mean overjet }(95 \% \mathrm{Cl}) \\
\text { at start/end of study }\end{array}$} & \multicolumn{2}{|c|}{$\begin{array}{l}\text { Mean PAR }(95 \% \mathrm{Cl}) \\
\text { at start/end of study }\end{array}$} \\
\hline & Start & End & Start & End \\
\hline $\begin{array}{l}\text { vin- } \\
\text { ock } \\
=89 \text { ) }\end{array}$ & $\begin{array}{r}+10 \\
(+9.70\end{array}$ & $\begin{array}{c}+3.70 \\
(+3.14-+4.25)\end{array}$ & $\begin{array}{c}31.15 \\
(29.03-32.26)\end{array}$ & $\begin{array}{c}18.04 \\
(16.24-19.84)\end{array}$ \\
\hline $\begin{array}{l}\text { Control } \\
(n=85)\end{array}$ & $\begin{array}{c}+10.41 \\
(+9.88-+10.93)\end{array}$ & $\begin{array}{c}+10.71 \\
(+10.13-+11.29)\end{array}$ & $\begin{array}{c}32.72 \\
(30.91-34.55)\end{array}$ & $\begin{array}{c}35.70 \\
(33.94-37.46)\end{array}$ \\
\hline
\end{tabular}

$\mathrm{Cl}$, Confidence interval.

Conclusions Early treatment with the twin-block appliance is effective in reducing overjet and severity of malocclusion. The small change in the skeletal relationship might not be considered clinically significant.

\section{Commentary}

At the best of times, early treatment is a controversial and prickly issue, much argued and debated yet lacking definitive outcomes. To see such an elegant and thought-provoking study reaffirms one's faith in the principles of evidence-based practice.

There is no doubt that if any treatment modality is to be assessed, efficiency and effectiveness are the measures on which its success must be rated. The authors stated the aim of their investigation as determining the effectiveness of early orthodontic treatment using the twin-block appliance. It would also be interesting to understand whether the twin-block is a good intervention with which to achieve a large average improvement, giving excellent outcomes to a major proportion of patients. Perhaps this would have to be balanced against the efficiency as reflected by costs in time and effort, number of visits and the discomfort experience.

The study was carefully structured and randomised with all the participants being accounted for. The fact that this was a multicentre study in itself adds to the strength of randomisation and elimination of bias, even when weighed against the possibility of interoperator variability.

The authors tried to retain pragmatic criteria for standardisation of results and the data analysis. The results reinforce the trend seen in a number of current publications. Skeletal change is not clinically significant, but the twin-block appliance is effective in reducing the overjet and the severity of malocclusion, reflected by the improved occlusal relationship and the overjet reduction. Most of the changes elicited are dentoalveolar.

It is especially interesting that one of the conclusions drawn by the authors is that early functional appliance treatment does not, on an average, influence a skeletal class II pattern at any degree of clinical significance. So can one derive a clinical bottom line? After all, there has been a preoccupation in orthodontics about the concept of growth modulation and redirection especially in cases of deficient mandibles. If the changes in early treatment are only dentoalveolar with the twin-block, then is this the most efficient way to manage the problem? There is a host of literature available that indicates that overall duration of treatment combining phases 1 and 2 is longer than a comprehensive single-phase treatment and the outcomes are no better. ${ }^{1,2}$

The authors concluded that, for a fairly high proportion of patients undergoing early twin-block treatment, the treatment will not be successful because of the non-compliance rate, here recorded to be $16 \%$. Again, to judge the cases with the PAR index would mean a quantification of five specific traits of malocclusion with highest weight ascribed to overjet. If the entire objective of a first phase of treatment was to reduce the overjet and influence dentoalveolar changes giving improved occlusal outcomes, then perhaps fixed appliances on a $2 \times 4$ concept would be more efficient and perhaps equally effective. It has been suggested that functional appliance patients would probably benefit from a single phase of treatment with more contemporary orthodontic appliances.
Address for correspondence: Professor Kevin O'Brien, Professor and Chair, Orthodontic Unit, University Dental Hospital of Manchester, Manchester M15 6FH, UK E-mail: kevin.o'brien@man.ac.uk 
The study is brilliant in concept, planning and execution. It is obvious that if the purpose of good science is to be continually reflective and curious, then this work stimulates a host of questions - as Lysle Johnston puts it, "answers in search of questioners". The controversy surrounding early treatment will only be resolved from sound and well-conducted studies like this one.

\section{Practice point}

- Skeletal change is not clinically significant, but the twin-block appliance is effective in reducing the overjet and the severity of malocclusion.

\section{Anmol Kalha}

Department of Orthodontics and Dentofacial Orthopaedics, College of Dental Sciences, Davangere, Karnataka, India

1. Vig K. One- or two-phase orthodontic treatment for class II malocclusion does no change the occlusal outcome. I Evid Base Dent Pract 2004; 2:142-143.

2. Chen JY, Will LA, Niederman R. Analysis of efficacy of functional appliances on mandibular growth. Am J Orthod Dentofacial Orthop 2002; 122:470-476.

Evidence-Based Dentistry (2004) 5, 102-103.

doi:10.1038/sj.ebd.6400302 